American Journal of Applied Sciences 8 (8): 777-781, 2011

ISSN 1546-9239

(C) 2011 Science Publications

\title{
Investigation of Nano Structural Changes by Annealing Temperature and Uniform Oxygen Flow on Ti Layers
}

\author{
${ }^{1}$ Haleh Kangarlou and ${ }^{2}$ Saeid Rafizadeh \\ ${ }^{1}$ Faculty of Science, Urmia Branch, I.A.U, Urmia, Iran \\ ${ }^{2}$ Faculty of Engineering, Urmia Branch, I.A.U, Urmia, Iran
}

\begin{abstract}
Problem statement: Ti films of the same thickness, deposition angle (near normal) and deposition rate were deposited on glass substrates at room temperature under UHV conditions. Approach: Different annealing temperatures $423 \mathrm{~K}, 523 \mathrm{~K}$ and $623 \mathrm{~K}$ with uniform $7 \mathrm{~cm}^{3} \mathrm{sec}^{-1}$, oxygen flow, were used to produce titanium oxide layers. Results: Thin film structures were studied using AFM, XRD and spectrophotometer methods. Roughness of the films changed due to annealing process. Conclusion/Recommendations: The getting property of Ti and annealing temperature can play an important role on the structure of the films.
\end{abstract}

Key words: Titanium dioxide, Thin films, AFM, XRD

\section{INTRODUCTION}

Thin metal oxide films over metal and semiconductor surfaces are probably the most widely studied structures in basic physics and technology. The reason is quite simple; their applications cover areas of interest such as catalysis (Linsebigler et al., 1995), dye sensitized solar cells (Sung and Kim, 2007), dielectric applications (Yang and Wolden, 2006) medicine (Muller and Hauert, 1996; Hanawa and Ota, 1992), anti reflection coatings (Ray et al., 2007). Metal-metal oxide structures involving titanium (Ti) are among the most interesting and used ones. Thus, the surface oxide passivation of Ti makes possible the biocompatibility of $\mathrm{Ti}$ and its use in medicine and the production of protective coatings against corrosion (Espinos et al., 1993). Titanium dioxide has interesting optical properties, for its high refractive index, wide band gap and highly transparent, that can be use in heat mirrors (Okada et al., 2006). Since most of the useful properties are determined by phenomena occurring at the surface, the kinetic and thermodynamic features of the oxide films growth and chemical reactions at the surfaces are key facts in most of these processes (Ye et al., 2007; Habibi et al., 2007). These chemical reactions can be greatly affected by the incidence of energetic particles or photons. These reactions can be either oxidation or reduction depending on the particular substrate. Thus, while in electron lithography the desired effect is the metallic reduction (Vergara et al., 2004), the electron bombardment can enhance by several orders of magnitude the oxidation kinetic of a semiconductor (Passeggi et al., 1993; Passeggi et al., 1998). The identification of the different products appearing in the growth of oxide films, as well as in the different reaction occurring at surfaces, allows us a better understanding of the different processes and, at the same time, opens the possibility of designing reliable growth and characterization methods. As known, $\mathrm{TiO}_{2}$ crystallizes in three different crystallo- graphic structures: brookite (orthorhombic), rutile (tetragonal) and anatase (tetragonal). Brookite is formed only in extreme preparation conditions, while rutile is the most common $\mathrm{TiO}_{2}$ crystal phase in nature. Anatase is metastable and thus it can be synthesized only in the restricted range of growth conditions.

In this study we want to study the influence of annealing temperature and oxygen flow on nano structure and roughness of produced layers and also crystallographic directions and reflectance of these nano layers and their dependence to mentioned parameters In this study we want to study the influence of annealing temperature and oxygen flow on nano structure and roughness of produced layers and also crystallographic directions and reflectance of these nano layers and their dependence to mentioned parameters.

\section{MATERIALS AND METHODS}

Titanium films of $70.3 \mathrm{~nm}$ thickness were deposited on glass substrates at room temperature. The residual gas was composed mainly of $\mathrm{H}_{2}, \mathrm{H}_{2} \mathrm{O}, \mathrm{CO}$ and $\mathrm{CO}_{2}$ as detected by the quad ro pole mass spectrometer. The substrate normal was at 8 degree to the direction of the evaporated beam and the distance between the 
evaporation crucible and substrate was $40 \mathrm{~cm}$. Just before use all glass substrates were ultrasonically cleaned in heated acetone, then ethanol. Other deposition conditions were the same during coating. Vacuum pressure was about $3 \times 10^{-6}$ tour and deposition rate was $1.5 \mathrm{~A}^{\%} / \mathrm{sec}$. Thickness of the layers were determined using quartz crystal technique. Annealing oven and different annealing temperatures $(423 \mathrm{~K}, 523$ $\mathrm{K}$ and $623 \mathrm{~K}$ ) and uniform oxygen flow were used to change nano structure of layers from titane to titania. The layers reach to a definite temperature in 3 hours. The layers will be kept in definite temperature for 2 hours in presence of oxygen flow and then the temperature decreases with a low rate to room temperature without oxygen flow.The nanostructure of these films was obtained using a Philips XRD X'pert MPD Diffractometer $\left(\mathrm{CuK}_{\alpha}\right.$ radiation) with a step size of 0.03 and count time of $1 \mathrm{~s}$ per step, while the surface physical morphology and roughness was obtained by means of AFM (Dual Scope ${ }^{\mathrm{TM}}$ DS 95-200/50) analysis. The near normal incidence reflectance spectra is obtained using a double beam spectrophotometer (carry 500 ) in the spectral range $200-2500 \mathrm{~nm}$ wave length corresponding to the energy range of $0.6 \mathrm{eV}-6.215 \mathrm{eV}$.

\section{RESULTS AND DISCUSSION}

Structural properties: Figure 1a-d shows the morphology of the produced layers (AFM). Figure 1a, shows the AFM image of as deposited Ti film, in room temperature and $70.3 \mathrm{~nm}$ thickness. As it can be seen, the surface is full of small domed grains. By increasing annealing temperature to $423 \mathrm{~K}$ and in presence of uniform oxygen flow $\left(7 \mathrm{Cm}^{3} \mathrm{sec}^{-1}\right)$ oxygen will penetrate to the grain structure and brake them down to tinnier needle like grains (Fig. 1b). In Fig. 1c annealing temperature increases to $523 \mathrm{~K}$ and as it can be seen the grains are domed and clearly bigger. This is because of surface diffusion in this temperature and oxygen penetration to layer structure. Figure $1 \mathrm{~d}$ shows the produced layer with $623 \mathrm{~K}$ annealing temperature, as it can be seen because of surface diffusion and more migration of grains, in higher temperature there are big piles and little domed grains together and growing effect is clearly obvious. By penetrating oxygen to the grain structure at $423 \mathrm{k}$ annealing temperature, grains break down to tinier grains and titanium dioxide begin to produce. By increasing annealing temperature to 523 $\mathrm{k}$ and $623 \mathrm{k}$ due to competition between penetrating oxygen and surface and bulk diffusion the grains become larger and specially at $623 \mathrm{k}$ growing effect appears.

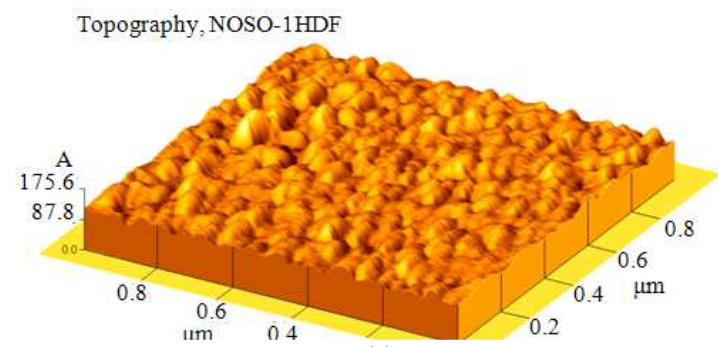

(a)

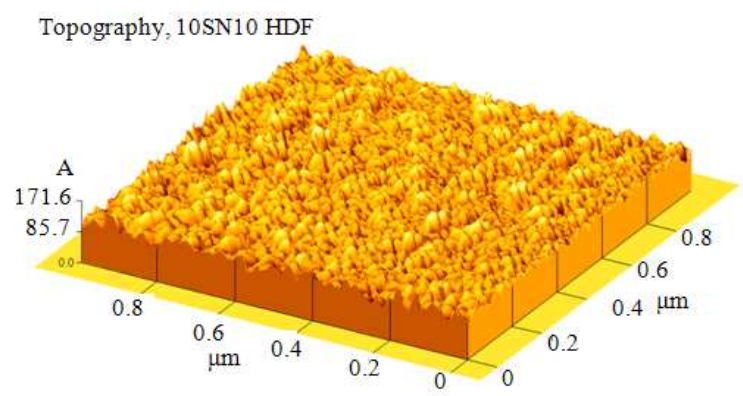

(b)
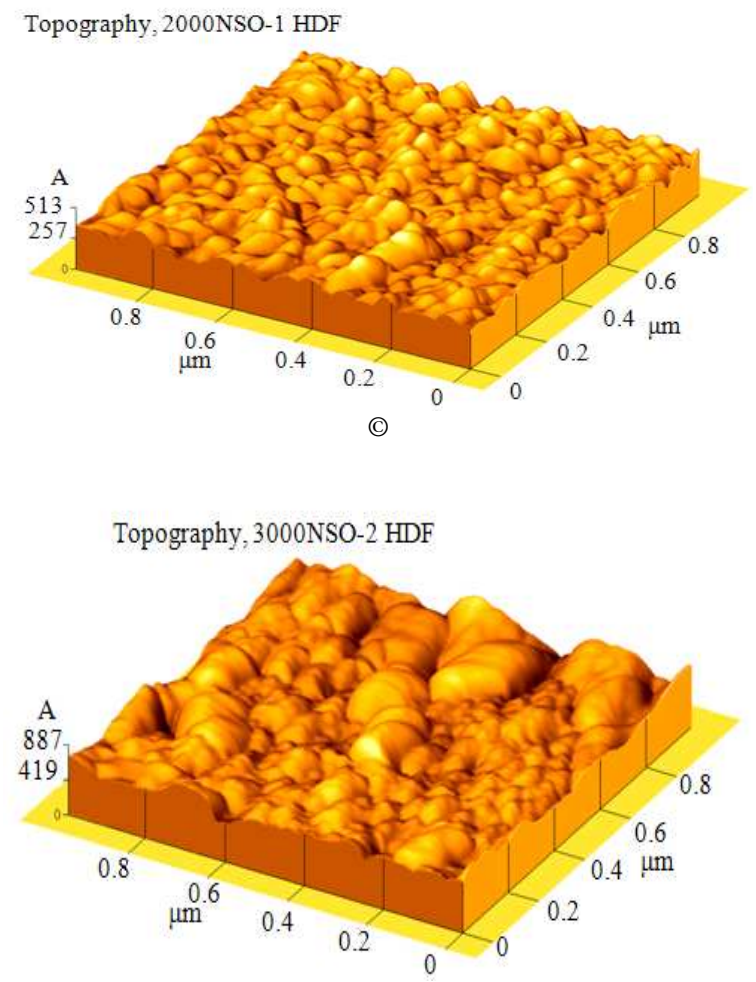

(d)

Fig. 1: AFM images of the as-deposited Ti film (a) and films annealed at $423 \mathrm{~K}$ (b), $523 \mathrm{~K}$ (c) and $623 \mathrm{~K}$ (d). The flow rate of oxygen during annealing was the same for all films, $7 \mathrm{~cm}^{3} \mathrm{sec}^{-1}$ 
Am. J. Applied Sci., 8 (8): 777-781, 2011

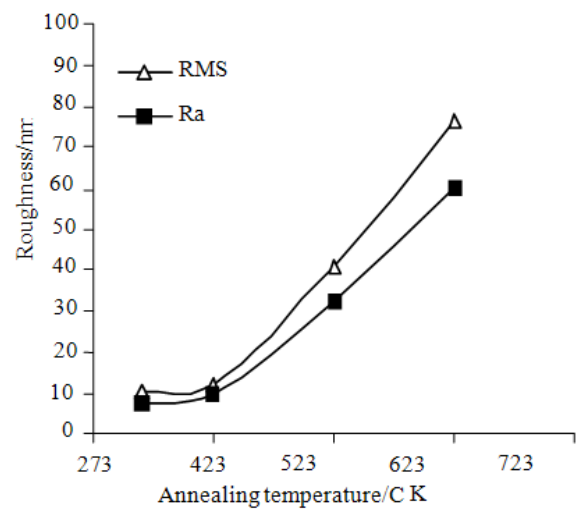

Fig. 2: The roughness diagram of the as-deposited Ti film (a) and films annealed at $423 \mathrm{~K}$ (b), $523 \mathrm{~K}$ (c) and $623 \mathrm{~K}(\mathrm{~d})$. The flow rate of oxygen during annealing was the same for all films, $7 \mathrm{~cm}^{3} \mathrm{sec}^{-1}$

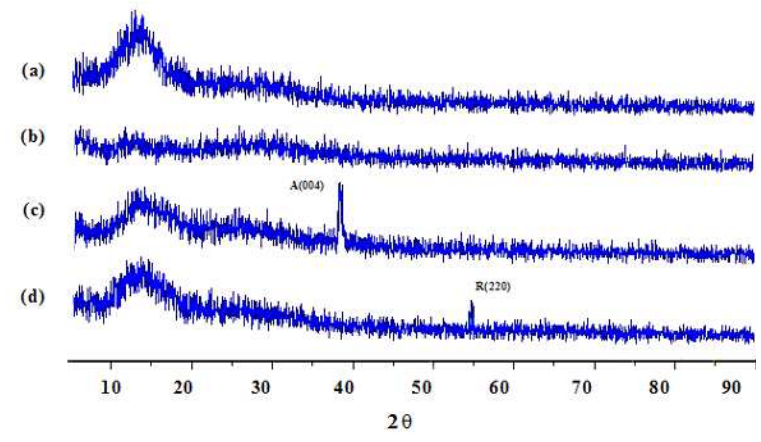

Fig..3: The XRD patterns of the as-deposited Ti film (a) and films annealed at $423 \mathrm{~K}$ (b), $523 \mathrm{~K}$ (c) and $623 \mathrm{~K}$ (d). The flow rate of oxygen during annealing was the same for all films, $7 \mathrm{~cm}^{3} \mathrm{sec}^{-1}$

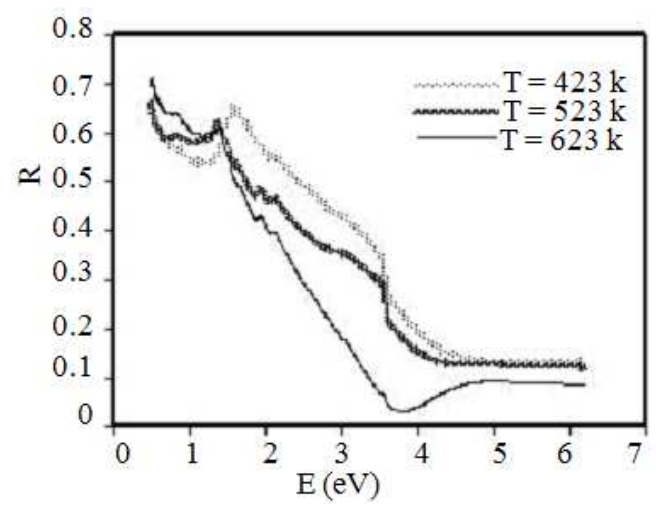

Fig. 4: The reflectance diagram of the films annealed at $423 \mathrm{~K}(\mathrm{a}), 523 \mathrm{~K}$ (b) and $623 \mathrm{~K}$ (c). The flow rate of oxygen during annealing was the same for all films, $7 \mathrm{~cm}^{3} \mathrm{sec}^{-1}$
Figure 2 shows the diagram of the roughness for the layers in this study. By increasing annealing temperature to $423 \mathrm{~K}$, roughness is almost the same as, initial $\mathrm{Ti}$ thin layer. By increasing annealing temperature to $523 \mathrm{~K}$ and $623 \mathrm{~K}$ roughness is also increasing, that is because of oxygen penetration to grain structure and migration of grains in high temperature and that is in agreement with AFM images.

As we know $\mathrm{Ti}$ is a getter metal and in presence of oxygen and heat will be converted to titanium dioxide. Figure 3a-d, shows XRD images for the layers in this study.

As it can be seen in Fig. 3a and b for as deposited $\mathrm{Ti}$ thin layer and $423 \mathrm{~K}$ annealing temperature in presence of oxygen flow, respectively there are no crystallographic direction and these layers are amorphous. By increasing annealing temperature to 523 $\mathrm{K}$ in Fig. 3c, an anatase $\mathrm{A}(004)$ crystallographic direction is obvious (Amor et al., 2003). And by increasing annealing temperature to $623 \mathrm{~K}$ in presence of uniform oxygen flow, it seems titanium dioxide anatase structure is converted to rutile structure and $R(220)$ crystallographic direction is beginning (Fig. 3d).

Figure 4 shows the reflectance of titanium dioxide layers in different annealing temperatures in presence of uniform oxygen flow. As it can be seen, by increasing annealing temperature, general trend of reflectance is decreased, this is because oxygen penetration to grain structures as an defect and by increasing temperature and migration of grains more holes are configured on the layers and thereupon transmittance increases and reflectance decreases.

Mechanical stability: Virtually all vacuum deposited coatings are in a state of stress. The total stress is composed of a thermal stress and an intrinsic stress. The thermal stress is due to the difference in the thermal expansion coefficients of the coating and substrate materials. The intrinsic stress is due to the accumulating effect of the crystallographic flaws that are built in to the coating during deposition. The residual stress is the sum of thermal stress and intrinsic stress (Thornton and Hoffman, 1989). By increasing temperature thermal stress increases and by penetrating oxygen in to grains and grain binderies intrinsic stress increases (Thornton and Hoffman, 1989), also phase transition, crystallization and grain size causes stress (Lapostolle et al., 2000), so for layers prepared in this study, actually we expect an increase for residual stress in layers. On the other hand, by increasing annealing temperature compressive stress decreases (Lee et al., 2005). For Titanium dioxide thin layers, by increasing annealing temperature, lower sub oxides began to 
capture oxygen and form stable oxides, that tends to a decrease in residual stress (Ottermann and Bange, 1996). If layers put in very high temperature specially for long time, residual stress will increase that tends to hillocks and cracks on the layers (Maier-Schneider et al., 1995). For the layers prepared in this study, by oxygen penetration, intrinsic stress increases, but oxygen flow is uniform for all samples, there for by increasing annealing temperature, residual stress will decrease. As it can be seen from AFM images (Fig. 1ad), there is no crack or hillocks on layers and in Fig. 1d growing effect appeared, that is because of surface and bulk diffusion in presence of high temperature.

\section{CONCLUSION}

The influence of annealing temperature and uniform oxygen flow on titanium layers with the same thickness were obtained. This was accomplished by the studying the relationship between AFM, XRD and spectrophotometer results. The morphology of the layers changes by increasing heat (annealing temperature) and presence of uniform oxygen flow. By increasing annealing temperature and presence of oxygen flow, in the first step oxygen penetrate to grains and brake them down to needle like grains, by increasing heat, because of surface diffusion, grains get domed and bigger more heat $(623 \mathrm{~K})$, causes big piles and little domed grains together and growing effect is clearly obvious. Roughness increases by increasing annealing temperature. Because of getting property of $\mathrm{Ti}$ and presence of oxygen flow and annealing processes, titanium dioxide layers produced. XRD patterns showed, amorphous layers for lower temperatures. By increasing temperature first anatase structure in $\mathrm{A}(004)$ crystallographic direction appeared and by increasing temperature to $623 \mathrm{~K}$, anatase phase is convertd to rutile phase and crystallographic direction is $\mathrm{R}(220)$. By increasing annealing temperature, because of oxygen penetration as an defect and migration of grains, more voids are configured on layers and reflectance decreases. Due to oxygen penetration intrinsic stress increases, but oxygen flow is uniform for all samples, there for by increasing annealing temperature, residual stress will decrease.

\section{REFERENCES}

Amor, S.B., L. Guedri, G. Baud, M. Gacquet and M. Ghedira, 2003. Influence of temperature on the properties of sputtered titanium oxide films. Mater. Chem. Phys., 77: 903-911. DOI: 10.1016/S02540584(02)00189-X
Espinos, J., A. Fernandez and A. Gonzalez, 1993. Oxidation and diffusion processes in nickeltitanium oxide systems. J. Surf. Sci., 295: 402-410. DOI: 10.1016/0039-6028(93)90287-T

Habibi, M.H., N. Talebian and J.H. Choi, 2007. The effect of annealing on photocatalytic properties of nano structured titanium dioxide thin films. Dyes Pigments, 73: 103-110. DOI: 10.1016/J.DYEPIG.2005.10.016

Hanawa, T. and M. Ota, 1992. Characterization of surface film formed on titanium in electrolyte using XPS. J. Applied Surf. Sci., 55: 269-276. DOI: 10.1016/0169-4332(92)90178-Z

Lapostolle, F., A. Billard and J. Stebut, 2000. Structure/mechanical properties relationship of titanium-oxygen coatings reactively sputtereddeposited. Surface Coatings Technol., 135: 1-7. DOI: 10.1016/S0257-8972(00)00721-0

Lee, C.-C., H.-C. Chen and C.-C. Jaing, 2005. Effect of thermal annealing on the optical properties and residual stress of $\mathrm{TiO} 2$ films produced by Ionassisted deposition. Applied Optics, 44: 29963000. DOI: 10.1364/AO.44.002996

Linsebigler, A., G. Lu and J. Yates, 1995. Photocatalysis on $\mathrm{TiO}_{2}$ surfaces: Principles, mechanisms and selected results. J. Chem. Rev., 95: 735-758. DOI: 10.1021/cr00035a013

Maier-Schneider, D., J. Maibach, E. Obermeier and D. Schneider, 1995. Variations in young's modulus and intrinsic stress of LPCVD-polysilicon due to high-temperature annealing. J. Micromechanics Microeng., 5: 121-125. DOI: 10.1088/0960$1317 / 5 / 2 / 016$

Muller, U. and R. Hauert, 1996. XPS Investigation of $\mathrm{TiO}_{2}$ containing dimond-like carbon. J. Thin Solid Films, 291: 323-327. http://www.cheric.org/research/tech/periodicals/vie w.php?seq=274752

Okada, M., M. Tazava, P. Jin, Y. Yamada and K. Yushimura, 2006. Fabrication of photocatalytic heat-mirror with $\mathrm{TiO}_{2} / \mathrm{TiN} / \mathrm{TiO}_{2}$ stacked layers. Vacuum, 80: 732-735. DOI: 10.1016/J.VACUUM.2005.11.014

Ottermann, C.R. and K. Bange, 1996. Correlation between the density of $\mathrm{TiO}_{2}$ films and their properties. Thin Solid Films, 286: 32-34. DOI: 10.1016/S0040-6090(96)08848-7

Passeggi, M.C.G., I. Vaquila and J. Ferron, 1998. Auger electron spectroscopy analysis of the first stages of thermally stimulated oxidation of GaAs(100). J. Applied Surf. Sci., 133: 65-72. DOI: 10.1016/S0169-4332(98)00013-0 
Passeggi, M.C.G., J., I. Vaquila and J. Ferron, 1993. Auger electron spectroscopy and principle component analysis of the first stage of oxidation in GaAs(100). J. Surf. Interface Anal., 20: 761-765. DOI: 10.1002/sia.740200904

Ray, S., U. Dutta, R. Dus and P. Chatterjee, 2007. Modelling of experimentally measured optical characteristic of $\mathrm{ITO} / \mathrm{TiO}_{2}$ transparent multi layer heat shields. J. Phys. D: Applied Phys., 40: 24452451. DOI: $10.1088 / 0022-3727 / 40 / 8 / 006$

Sung, Y.M. and H.J. Kim, 2007. Sputter deposition and surface treatment of $\mathrm{TiO}_{2}$ films for dye-sensitized solar cells using reactive RF plasma. Thin Solid Films, 515: 4996-4999. DOI: 10.1016/J.TSF.2006.10.079
Thornton, J.A. and D.W. Hoffman, 1989. Stress related effects in thin films. Thin Solid Films, 171: 5-31. DOI: 10.1016/0040-6090(89)90030-8

Vergara, L.I, R. Vidal and J. Ferron, 2004. Electron induced reduction on $\mathrm{AlF}_{3}$ thin films. J. Applied Surf. Sci., 229: 301-310. DOI: 10.1016/J.APSUSC.2004.02.008

Yang, W. and C.A. Wolden, 2006. Plasma-enhanced chemical vapour deposition of $\mathrm{TiO}_{2}$ thin films for dielectric applications. Thin Solid Films, 515: 1708-1713. DOI: 10.1016/J.TSF.2006.06.010

Ye, Q., P.Y. Liu, Z.F. Tang and L. Zhai, 2007. Hydrophilic properties of nano $\mathrm{TiO}_{2}$ thin films deposited by RF magnetron sputtering. Vacuum, 81: 627-631.

DOI: 